\title{
Building Healthy Northern Communities Through Strengthening Capacity
}

Glen Schmidt, Dawn Hemingway, Gerard Bellefeuille University of Northern British Columbia 


\begin{abstract}
This study examines and evaluates the effects of one-time funding on capacity building of health and social welfare organizations in a remote and northern section of British Columbia Canada. The Province of British Columbia awarded a two million dollar grant (Canadian) to the University of Northern British Columbia (UNBC). Organizations applied for funds through a competitive process that was managed by the School of Social Work at UNBC. Twenty-five different community organizations and agencies received funding for a period of eighteen months. The organizations and agencies delivered a range of services and activities located in remote First Nations communities as well as the natural resource-based single industry towns of northern BC. A reporting mechanism allowed UNBC to evaluate the use and application of the funds by the organizations and agencies that qualified for the capacity building project. Six years after the funding ended, the organizations and agencies were contacted and interviewed to see if the one-time funding had any lasting impact. Fourteen of the funded projects terminated; three continued to operate but at a greatly reduced level of activity; seven projects continued to operate after the funding ended; and one project was able to continue operation after acquiring a new source of funding. Case study examples are used to illustrate the outcomes of this project. The projects that were able to continue in a sustained manner used volunteers or had an organizational structure that allowed the project to be incorporated into existing resources. The sustained projects also depended on collaboration with other organizations and support from the community as well as other health and social service providers. While this type of funding had some short-term benefits in capacity building, sustained delivery tended to rely on residual systems and resources, calling into question its usefulness.
\end{abstract}

\title{
Introduction
}

This paper reports on the outcomes of a funding partnership between the British Columbia Ministry of Children and Family Development (MCFD), the School of Social Work at the University of Northern British Columbia (UNBC), and non-profit organizations located across the North Region of British Columbia. The initiative was supported by a two million dollar grant that funded community-based projects designed to enhance the capacity of northern, rural, and remote communities to support vulnerable children and families.

Background of the project

British Columbia (BC) is the third largest of Canada's ten provinces. The oldest confirmed sites of human settlement date to 6000 BCE. People of European origin moved into the area following the discovery of gold in the interior of the province in 1858 . This settlement accelerated after completion of the Canadian Pacific Railroad in 1885. The most recent census reports the BC population at 4.1 million people (BC Stats). The North Region of the province is as large as the federal state of Germany but the population of northern BC is small numbering 274,000 . This number includes 48,050 people of Aboriginal ancestry, about $17.5 \%$ of the region's population. Many of the Aboriginal people live on remote reserves that have limited services and limited opportunities for employment. The City of Prince George is the largest community with 75,000 people. The people of northern $\mathrm{BC}$ live in widely dispersed communities with vast distances between settlements. Most of the communities depend on resource-based industries such as forestry, hydrocarbons, and mining. The people live in single industry towns that are susceptible to fluctuations in global markets and the demand for resource commodities. Health and social services are not as diverse or as abundant compared to large southern cities such as Vancouver, Kelowna, and Victoria.

In 2001 the BC Liberal Party was elected with a massive majority winning all but two seats in the 85 seat provincial legislature. During its tenure in opposition the Liberal Party was highly critical of the governing New Democratic Party's (NDP) management of child welfare services. An inquiry led by Justice Thomas Gove produced the Gove Report 
in 1995, which drew attention to many problems experienced by MCFD, then called the Ministry of Social Services. While in government, the NDP responded to Gove and embarked on a series of reforms to the structure and operation of the Ministry. Among the recommendations, MCFD was to become more child-focused and more responsive to communities through the development of community governance. MCFD operated in a highly centralized manner that was not regarded as responsive and attentive to the needs of communities. MCFD was divided into five geographic and administrative regions that roughly corresponded to Vancouver Island, the City of Vancouver and the area immediately north and south of Vancouver, the Fraser Valley (suburbs and communities running east of Vancouver), the southern interior and Kootenays (area from the US border to the Alberta boundary including urban centres like Kelowna), and finally the North. The North was the largest region in area taking in almost two-thirds of the Province.

The incoming Liberal government made reform and restructuring of MCFD a priority but the movement toward community governance was set within an overall policy framework of severe restraint. Within Canada, the term Liberal is generally associated with the Liberal Party of Canada. This is a national, federal party and it was the governing party through much of the twentieth century. Ideologically the Liberal Party of Canada locates itself in the middle of the political spectrum. Although moderately progressive on social issues, at times it might lean to the right on fiscal issues. For example, during the 1990s The Liberal Party of Canada embarked on a program of severe restraint that had a pronounced impact on a range of programs including social housing, health care, and education. At other times the Liberal Party of Canada has pursued fiscal policy that emphasized state intervention in the economy. For example, under Prime Minister Trudeau the Liberal government nationalized parts of the oil and gas industry. By way of contrast, the BC Liberal Party represented a coalition of conservative groups formed for the purpose of providing an alternative to the social democratic NDP. Ideologically the Liberal Party was committed to smaller government, lower taxes, deregulation, and reduced government services. In this respect it is somewhat different from the Liberal Party of Canada.

Initially MCFD was targeted for a massive budget reduction of $23 \%$, a goal that was later eased to $11 \%$. Despite dire warnings regarding the consequences, the government proceeded with its revised $11 \%$ target for budget reduction. By 2003 this figure was achieved and perhaps to reduce some of the political fallout or to reinforce its stated commitment to community innovation and control, the government decided to allocate ten million dollars to be equally distributed among what were then the five MCFD operating regions. The two million dollar grants had stated purposes that included: a wish to reduce the number of children and youth in care within the Ministry while ensuring their safety and well being; support projects that would build capacity in communities and families so that children and youth who were in the care of the Ministry of Children and Family Development might be returned to their community and their family; support families in the growth and development of healthy, safe children and youth; and support collaborative community projects that would prevent the necessity of high-risk children and youth from coming into care.

Each of the five MCFD operating regions was to identify a partner that would be responsible for distributing the funds, managing the program, and evaluating outcomes. In the North Region the Ministry of Children and Family Development approached the School of Social Work at UNBC to distribute and manage the grant fund. In discussion with MCFD, the University of Northern British Columbia developed the following funding principles in a call for proposals:

- The proposal will identify a specific target group that relates to community, children, and youth.

- The proposal will be time-limited to eighteen months following receipt of the funds.

- The proposal will include a detailed budget that meets generally accepted accounting principles. 
- The proposal will involve collaboration with other agencies or organizations in the community particularly in the areas of integrated case management and wrap around case management.

- The proposal will identify clear and measurable objectives with specific ways of measuring the objectives. Competent personnel will be in place to evaluate and measure the desired outcomes and the proposal will include a clear plan for quarterly reporting of information (financial and programmatic).

- No more than twenty percent of the proposed budget is to be allocated to supply and equipment costs.

- Participating agencies agree to submit information and data to the University of Northern British Columbia Social Work Program for analysis and dissemination.

- The proposal can request a maximum of $\$ 75,000.00$.

- The evaluation committee will ensure that there is an equitable distribution of funds through the Ministry of Children and Family Development's North Region.

- Applicants to the fund will be advised as soon as the review process is complete. A total of 86 proposals were received prior to the submission deadline. An independent panel of four people external to UNBC evaluated the proposals. The panel used a scoring formula to select organizations and projects for funding that was based on the following criteria:

- The proposal builds community or family capacity that will enable the return of children or youth currently in care.

- The proposal supports a collaborative community project that will prevent highrisk children and youth from coming intocare.

- The proposal supports families and communities in the growth of healthy safe children and youth.

- The proposal is coherent, congruent, and sound in its presentation.

- The proposal identifies clear and measurable objectives with specific ways of observing or measuring the objectives.

- Competent personnel will be in place to evaluate and measure the desired outcomes and the proposal will include a clear plan for quarterly reporting of information (financial and programmatic).

- The proposal is sustainable through volunteers or existing resources.

- The specific target group is clearly identified.

- The proposal will involve collaboration with other agencies or organizations in community particularly in the areas of integrated case management and wrap

the around case management.

The British Columbia Ministry of Children and Family Development was clearly interested in gaining some political advantage within the context of an environment of fiscal restraint. The politicians hoped to see some improvement in the delivery of child welfare services but they were unwilling to invest in publicly funded continuing programs. The implicit desire was to find ways to activate residual systems and invigorate existing publicly funded organizations. In this sense there was a desire to build capacity and develop social capital. The interest in the School of Social Work at UNBC was to determine if this type of approach was sustainable.

\section{Capacity}

The government's policy initiative designed to broaden the capacity of communities to protect vulnerable children and families took place at the same time that many other public social services were cut and socioeconomic changes increased the number of families with multiple service needs (Scott). Ideas regarding capacity building and sustainability emerged during a period of time when governments of all stripes were retreating from their responsibility for social welfare provision. In Canada, the federal government's role in funding the provision of social welfare services has substantially declined and more 
responsibility has shifted to the provinces. Increasingly, expectations are placed on community-based voluntary, charitable, and non-profit organizations to address social problems and needs (Bellefeuille and Hemingway; Chappell; Gill and Thériault). In the field of child welfare, the importance of encouraging communities to use local resources to build capacity to solve local problems has garnered significant political attention (Trocmé and Chamberland; Wharf).

Various definitions and frameworks for capacity development or capacity building have been advanced in recent years (Kaplan; Laverack; Pender, Murdaugh, and Parson; World Health Organization). For example, Rogers, Howard-Pitney, and Lee view capacity building as the transfer and development of knowledge, skills, systems, and resources to communities to effect change. For Frank and Smith capacity building is based on the premise that community sustainability can be improved over time. Others suggest that the notion of building capacity is context specific signifying, for instance, that a community's capacity to address day care issues may be different from its capacity to address child welfare issues (Goodman et al.; Parker, Eng, Schulz, and Israel). Popescu et al. define capacity building as activities that improve service delivery, expand services, and create sustainability.

Specific to the community empowerment literature, a capacity approach to community building is grounded in an assets-based model, which promotes recognition of the power and capabilities that individuals already possess (Kretzmann and McKnight). It sees community members as active change agents in the context of the constraints posed by existing social structures and power relations (Dunst, Trivette, and Deal). Fitzsimons and Fuller (2002, p. 483) describe the various dimensions of capacity development as requiring "increased knowledge, skills and personal growth, a better understanding of one's position in relation to the surrounding social and political forces, and enhanced perceptions of selfefficacy, personal control, self-esteem, and political efficacy." From a meta-analytic review of 56 evaluations conducted between 1979 and 1998 MacLeod, Nelson, and Desmarais (p. 1 ) concluded that "most interventions" aimed at promoting family wellness and preventing child maltreatment, "with an empowerment, strengths-based focus are more effective than expert driven, deficit based programs".

In the population health literature, capacity is recognized as a resource rather than a state, a definition that corresponds more to "the actual knowledge, skill sets, participation, leadership, and resources" required by community groups to effectively address local issues and concerns (Ontario Prevention Clearinghouse, p. 1). From a population health standpoint, community capacity must be strategically linked to the specific cluster of health determinants that are the most pivotal in creating the actual health conditions giving rise to the problems that need to be addressed (Bopp and Bopp). As such, population health strategies aim at improving health by making changes in modifiable risk factors and/or risk conditions (Chaskin; Easterling et al; Goodman et al.; Labonte, Woodard, Chad, and Laverack; Poole).

\section{Social Capital}

Social capital is a related term that often overlaps with the concept of capacity (Poland). The first theoretically refined sociological analysis of social capital was not produced until the 1980s, however, in Pierre Bourdieu's "Le Capital Social: Notes Provisoires." Bourdieu criticized economic theory for focusing only on economic capital. Instead, Bourdieu proposed the development of a general science of the economy of practices, capable of examining capital, understood as power, in all its forms. In Making Democracy Work (1993) and Bowling Alone (1995), Putnam makes the case for social capital's more heuristic value by challenging overly narrow economic models of development and democracy. Putnam defined social capital as "features of social life - networks, norms, and trust-that enable participants to act together more effectively to pursue shared objectives" (pp. 664-665). For Putnam, social associations, particularly those featuring face-to-face, "horizontal associations" between people, generate trust, norms of reciprocity, and a capacity for civic engagement. 


\section{Sustainability}

Building capacity requires sustainability because the individuals, groups, and organizations develop the abilities and resources to maintain community 'owned' initiatives (Rissel, Finnegan, and Bracht). An important and integral part of the analysis was the sustainable creation, utilization, and retention of the project-based community capacity building interventions. Claquin defines sustainability as the capacity to maintain service coverage at a level that will provide continuing control of a health problem. The World Bank defines sustainability as the capacity of a project to continue to deliver its intended benefits over a long period of time (Bamberger and Cheema). According to the US Agency for International Development, a development program is sustainable when it is able to deliver an appropriate level of benefits for an extended period of time after major financial, managerial, and technical assistance from an external donor is terminated. Gates and Lee define sustainability as the capacity to build and maintain resources that contribute to individual and community well-being and prevent the occurrence of future problems. Hawkins examines sustainability from a personal and family perspective and defines it as the ability to maximize full potential in order to realize long-term economic, physical, psychological, and social well-being. Most of the definitions suggest that sustainability incorporates change that has a degree of endurance or lasting effect. The definition applies to individuals, families, organizations, communities, and systems. Friedman and Schreiber note that without sustainability, program development is of little consequence.

\section{Research question}

This research is an examination of the 25 funded projects and asks the question: Which projects were able to demonstrate sustainability within an overall capacity building framework? Projects that appear to have developed in a sustainable manner will be described and the characteristics that promote sustainability identified.

\section{Research method}

Data collection sources included the initial proposal, quarterly activity reports, an evaluation survey, a personal interview with project managers at the conclusion of the funding period, and personal interviews with project managers six years after the funding concluded. The initial goals and objectives of each project were examined along with the activity reports, final evaluation surveys, and personal interviews with the project managers once project funding ceased and again six years later (in 2011). All data were analyzed to identify and categorize themes germane to the research question, with particular attention focused on sustainability. Content analysis was used to analyze the text data (White and Marsh). Different types of data recording units can be used in content analysis but in this case themes were the main unit employed in analyzing the text data. Case studies are presented based on the four thematic categories regarding sustainability. The characteristics of each category are described.

\section{Description of the projects}

The funds were allocated and divided to insure that the main geographic areas and population clusters of northern $\mathrm{BC}$ received a fair distribution of money. This division identified five sub-areas of the North Region: the Peace River area, the Prince George area, the Quesnel area, the Lakes and Bulkley Valley area, and the Northwest area. Forestry is an important industry throughout these sub-areas but hydrocarbons are a major industrial resource and source of economic activity in the Peace River area. There is some mining in all the areas. Aboriginal people live in all five sub-areas but the largest numbers are found in the Northwest.

The application for grant funds was a competitive process as 86 submissions were received but only 25 were funded. The projects received funding of up to $\$ 75,000.00$ for 18 months though the start-up dates for each project varied due to staff availability and 
other internal organization factors. All of the projects concluded in 2005. The projects broadly fell into one of four main activity areas:

- Skill training and enhancement of staff and allied resources

- Development of a new program

- Enhancement or expansion of an existing program

- Community and client education

The funded projects represented a range of different northern organizations as displayed in the following table:

\section{Table 1}

Funded Organizations

\begin{tabular}{|l|l|l|l|l|l|l|}
\hline $\begin{array}{l}\text { Type of } \\
\text { Organization }\end{array}$ & $\begin{array}{l}\text { Peace } \\
\text { Region }\end{array}$ & $\begin{array}{l}\text { Prince George } \\
\text { Region }\end{array}$ & $\begin{array}{l}\text { Quesnel } \\
\text { Region }\end{array}$ & $\begin{array}{l}\text { Bulkley Valleyl } \\
\text { Lakes Region }\end{array}$ & $\begin{array}{l}\text { Northwest } \\
\text { Region }\end{array}$ & Total \\
\hline Aboriginal & 2 & 1 & 0 & 1 & 4 & 8 \\
\hline Non-Profit & 4 & 7 & 1 & 1 & 2 & 15 \\
\hline Education & 0 & 0 & 0 & 2 & 0 & 2 \\
\hline Total & 6 & 8 & 1 & 4 & 6 & 25 \\
\hline
\end{tabular}

The Aboriginal organizations included First Nations Bands, First Nations Family Service agencies, and Friendship Centres. While Friendship Centres are not exclusively Aboriginal, those in northern $\mathrm{BC}$ are predominantly run by Aboriginal people and deliver services designed to meet the needs of Aboriginal people.

The non-profit organizations ranged from small child development agencies through to local branches of large national or international organizations. The education organizations included a school district program as well as a community college program. Organization budgets ranged from less than $\$ 100,000.00$ per year to millions of dollars in the case of a school district.

The funded projects delivered direct service to clients as well as volunteers, professionals, paraprofessionals, and agencies. The services delivered to volunteers, professionals, and paraprofessionals involved a range of education and training activities. In total 308 professionals, volunteers, and paraprofessionals received service during the course of this project. Some examples included specialized training for volunteers that targeted children with special needs; team development and team building training; and training in delivery of parenting programs. The services to organizations involved provision of materials and orientation to particular programs as well as public awareness regarding child welfare issues. For example, one organization delivered a program to other agencies and organizations designed to prevent child abuse through educating volunteers, coaches, board members, and officials. The services to individuals and families included advocacy, support, skills training, and education in a variety of areas, especially parenting. Two organizations addressed fathers, which was an important development as parenting programs for fathers are rare in northern BC. One First Nation that experienced negative effects resulting from the federal government residential school policy, obtained and modified a program designed to educate and enhance the skills of Aboriginal parents. This was delivered to 110 parents in the community.

The number of clients that received service as a result of the various projects developed and delivered by the organizations participating in this program, ranged from a low of 16 to a high of 2500 . The dispersal of funds through five sub-regions meant that there was a fairly widespread distribution of projects in northern BC. 


\section{Sustainability as an outcome}

Sustainability can be examined from a number of different perspectives. Sustainability involves changes to agency practice, employee practice, client capacity, and overall community capacity. Scerri and James argue that while governments look for quantitative measures to determine and evaluate sustainability, a true measure of sustainability is qualitative as well as quantitative. Sustainability within this context has varying degrees of endurance and it is difficult if not impossible to measure given many intervening and confounding variables. For example, in one project fathers attended a group designed to enhance their capacity to parent. The educational content of the program provided the fathers with knowledge about child development, child behaviour, age appropriate activities, communicating with children, and managing child behaviour issues. The group also created a connection among fathers, which led to mutual support and social contact outside the formal group setting. The enduring sustainability of the knowledge as well as the social connection is difficult to evaluate over the longer term.

Sustainability connected to delivery of a specific program is much easier to assess as this can be described through evaluating the endurance and continuance of a specific program. The receipt of funds from this grant produced four distinct program-sustainability outcomes. First, there were programs, activities, and initiatives that ceased to operate with the exhaustion of the funds. Second, there were programs that declined in overall activity and capacity but continued to survive at a reduced level of delivery. In these instances programs were cut or shifted to other departments or staff where they did not receive the same input or priority. Third, there were programs that continued to operate and even expand in terms of delivery or presence. These programs found ways to maintain the initiative that was facilitated by the one-time injection of funds. Fourth, there was one program that continued to operate as a result of obtaining an additional source of funding. Many of the applications, including successful proposals that received funding, established a goal or objective of finding and securing additional funding that would enable their project to continue. However, this proved difficult to achieve. The results using the four outcomes described above are displayed in Tables 2, 3 and 4.

\section{Table 2}

Program Sustainability by Region

\begin{tabular}{|l|l|l|l|l|l|l|}
\hline Outcome & $\begin{array}{l}\text { Peace } \\
\text { Region }\end{array}$ & $\begin{array}{l}\text { Prince George } \\
\text { Region }\end{array}$ & $\begin{array}{l}\text { Quesnel } \\
\text { Region }\end{array}$ & $\begin{array}{l}\text { Bulkley Valley/ } \\
\text { Lakes Region }\end{array}$ & $\begin{array}{l}\text { Northwest } \\
\text { Region }\end{array}$ & Total \\
\hline Termination & 4 & 5 & 1 & 1 & 3 & 14 \\
\hline $\begin{array}{l}\text { Reduced } \\
\text { Activity }\end{array}$ & & 1 & & 1 & 1 & 3 \\
\hline Continuation & 2 & 2 & & 2 & 1 & 7 \\
\hline New Funds & & & & & 1 & 1 \\
\hline
\end{tabular}

Table 3

Program Sustainability by Type of Organization

\begin{tabular}{|l|l|l|l|}
\hline Outcome & Aboriginal & Non-Profit & Education \\
\hline Termination & 5 & 8 & 1 \\
\hline Reduced Activity & & 3 & \\
\hline Continuation & 2 & 4 & 1 \\
\hline New Funds & 1 & & \\
\hline
\end{tabular}


Table 4

Type of Project by Activity Area

\begin{tabular}{|l|l|l|l|l|}
\hline Activity & Training & $\begin{array}{l}\text { Program } \\
\text { Development }\end{array}$ & $\begin{array}{l}\text { Program } \\
\text { Enhancement }\end{array}$ & Client Education \\
\hline Outcome & & & & \\
\hline Termination & 2 & 2 & 1 & 9 \\
\hline Reduced Activity & & 1 & 2 & \\
\hline Continuation & 2 & 3 & 2 & 1 \\
\hline New Funds & & & & \\
\hline
\end{tabular}

\section{Case Studies}

The case studies are based on information gathered through the termination interviews, the interviews conducted six years after termination (in 2011), and examination of documentation provided through the duration of the projects.

\section{Termination}

The projects that terminated following the exhaustion of funds shared the same basic characteristics. One characteristic was that the projects used the funds to hire an employee or employees to deliver and in some cases develop a specific program. In the initial proposal the organizations indicated that they would be able to find additional funds or reallocate resources to continue the program. In almost all instances this did not happen. One project was able to obtain new funds to continue employing a staff person who provided client education and advocacy services. However, this was the exception.

A second characteristic of projects that terminated was that they used the money to hire external trainers or educators to deliver a program or specialized service to an identified group. For example, one First Nations organization hired an external consultant to deliver a training program for parents with special needs. This particular organization had a number of parents who were hearing impaired and had children in care. The isolated northern location of the First Nation and the lack of local resources to deliver a parenting program that incorporated signing communication was a severe restriction. The program funds enabled the organization to hire specialists on contract, which resulted in increased parenting capacity and in one case, return of children who had been in care. However, with the exhaustion of the fund the capacity and ability to deliver this type of service disappeared. It was not sustainable given the dependence on a specialized, external, contracted resource.

\section{Reduced activity}

A second group or category of projects involved organizations that had to reduce activity after they were able to develop a program or enhance an existing program with the project funds. With the termination of the funds these organizations had to cut back and reduce the level of program activity. For example, one organization delivered a program that supported and taught low-income parents to read to their pre-school age children. The fund enabled a staff person to spend time training volunteers to run these groups and to directly operate the groups. However, once the fund was terminated the number of groups that the organization was able to operate each budget year was reduced from 11 to 4 . The program was sustained but at a diminished capacity. Like those projects that terminated, this type of project increased individual, family, and community capacity but the degree to which this will be sustainable or endure over time is difficult to assess.

Another example related to training volunteers to provide support to families at risk of having their children come into care due to concerns regarding neglect. Materials and 
curriculum were developed and continue to be available for public use. However, the lack of continued funding is a problem, as the organization does not have a staff resource to conduct the training. The material or artifacts developed by the program remain but are not used to any great extent due to lack of a staff resource.

\section{Continuation}

The third category of project and the type that is of greatest interest involves projects that were able to continue once the funds were exhausted. The continuity of these projects could be attributed to a number of factors best illustrated by describing three examples of sustained capacity.

In the first example, the organization developed a group art program for foster children with a diagnosis of Fetal Alcohol Spectrum Disorder. The funds enabled the organization to hire a staff person with the specific task of developing the program. Program development involved recruitment of local artists willing to volunteer their time and skills, training volunteers who were interested in this type of approach, and advertising the program among local social workers and social service agencies. Once the program was developed and established it was incorporated into the regular operations of the agency and required no additional funds to sustain. It quickly became a credible program supported by child welfare social workers. The training capacity and volunteer nature of the organization allowed it to add this as a program variation within the existing structure. The program is likely to be maintained over the longer term without the need for additional funds.

In a second example, a large organization funded a facilitator to provide training in an assessment protocol or model designed to increase safety of children in the community. The training program was extensively advertized among local organizations and their staff were encouraged to participate in the training. The training was dynamic and it also involved training trainers. Existing agency staff members became qualified trainers and the strong interest and support among the broader community allowed this program to continue in an effective and sustained manner. The trainers have been able to train other staff so that the program continues even when people retire or leave the organization. The program continues to operate effectively even after the funding terminated.

In a third example, a small non-profit society developed a proposal to create an inter-agency group that would address children at risk by developing a structure for improved communication, collaboration, and coordination among community agencies. The project involved hiring a staff person to meet with the various agencies, gather ideas, facilitate community meetings, develop a structure for inter-agency collaboration, and coordinate the inter-agency meetings. The inter-agency group became a viable operation and when funding for the staff position terminated, the inter-agency group continued to operate. In this case the coordination for continuing the inter-agency meetings was taken on by permanent staff without additional funding. In fairness it meant adding to the workload but due to the establishment of a workable structure, it did not create an unmanageable burden. The introduction of the temporary staff position enhanced the organization's ability to develop a structural component that permanent staff did not have time to pursue. It should also be noted that this organization has experienced staff stability in that the Executive Director and Project Manager remain in their positions after six years. This type of stability also seems to help in promoting sustainability, as there is often a more personal investment in the initiative.

The successful projects in terms of continuation did not develop new programs that were completely dependent on paid staff positions. They built on existing infrastructure, or used a temporary staff resource to build new infrastructure, and they made extensive use of volunteers and community members. The continuing projects were collaborative in nature and developed strong support within the community. 


\section{New funds}

As noted, only one project successfully obtained a new source of funding to continue activity. Many of the projects set the acquisition of new funds as a goal but this was difficult to achieve. In the six-year follow-up interviews, organizations indicated that they increased their skills and knowledge in grant and proposal writing out of necessity. Increasingly small non-profit societies are finding that they have to depend on temporary grants. Funding organizations such as the United Way once funded programs on a fairly permanent basis. Now such funding organizations tend to look at providing temporary money that may be in place for one or two years with an expectation that the agency will find a different source for permanent funding.

\section{Discussion}

The results of this project are mixed but sustaining capacity is connected to a number of characteristics. More than half, a total of 14, of the 25 projects terminated following exhaustion of the funds. Seven of the projects continued to operate at more or less the same level of intensity. Another project was able to continue once it found a new source of ongoing funding. Four additional projects continued but at significantly reduced levels of activity. The results demonstrate that new programs, which depend upon specialized paid staff resources, are not likely to be sustainable once funds terminate. It is important to recognize that these types of programs do have a positive impact but it is not clear whether the impact is enduring.

An unintended but important outcome of the project involved skill in grant and proposal writing. In a six-year follow-up interview a program manager said, "This was the first time our organization developed this type of proposal. We've done quite a number since and we're getting pretty good at it."

With this type of temporary funding, continuity and sustainability depend upon the ability of an organization to create programs or structures that can be sustained through the use of volunteers. Organizations that developed or had a volunteer system in place were more likely to be successful. Sustainability also occurred if existing staff were able to assume responsibility for the program without excessive burden or additional responsibility. The example of establishing the inter-agency group illustrates this type of sustained operation. The funding allowed the structure of the group to be developed, integrated, and sustained as part of the community social service culture.

Finally, community support and collaboration with other agencies is also important in the creation of a sustainable program. In the six-year follow up interviews project managers talked about the importance of gaining and holding the support of other groups within the community as a means to support continuity of a project or program. However, attaining and sustaining such support can be challenging given shrinking social service funding available almost exclusively through competitive government granting processes that pit one agency against another.

Findings suggest that a level of sustainability can be achieved by developing resources that are used by volunteers and existing agency or organization personnel. However, the effects of this "more with less approach" must be questioned. For example, how many volunteers can a small northern community maintain and sustain? When do volunteers reach a point of exhaustion? When do volunteers overreach their own capacity in terms knowledge and skills? How much additional work can you assign to already overtaxed and overburdened staff? And most importantly, with the wealth gleaned by government treasuries through taxation, forestry stumpage fees, and other resource-based revenues and by huge resource monopolies via timber licenses and mineral rights, why should northern communities have to rely on volunteers and initiatives of overworked staff to provide and sustain necessary social services?

The examination of the sustainability of these one-time funded projects suggests that while there were some benefits, the general results were discouraging. It points to the need for ongoing core funding in the delivery of services that build capacity and social capital. 


\section{References}

- Bamberger, Michael and Cheema, Shabbir. Case Studies of Project Sustainability: Implications for Policy and Operations from Asian Experience. Washington, DC: The World Bank, 1990. Print.

- B.C. Stats. Census Index 2006. Web. 15 July 2010.

- Bellefeuille, Gerard and Hemingway, Dawn. "The New Politics of Community-Based Governance Requires a Fundamental Shift in the Nature and Character of the Administrative Bureaucracy." Children and Youth Services Review 27.5 (2005): 491-498. Print.

- Bopp, Michael and Bopp, Judie. "Welcome to de swamp. Why measuring community capacity is fundamental to transformational work." Community-Level Indicators: Building Community Capacity for Health Conference October 15 - 17, 2002 Jasper, Alberta.

- Bourdieu, Pierre. "Le capital social: notes provisoires." Actes de la recherche ensciences sociale, 31 (1980): 2-3. Print.

- Bourdieu, Pierre. "The Forms of Capital." Handbook of Theory and Research for the Sociology of Education. Ed. John Richardson. New York: Greenwood, 1986. 241-258. Print.

- Chappell, Rosalie. Social Welfare in Canadian Society. 2nd ed. Scarborough, Ontario: Thomson Canada Ltd, 2001. Print.

- Chaskin, Robert. "Building Community Capacity: A Definitional Framework and Case Studies from a Comprehensive Community Initiative." Urban Affairs Review 36.3 (2001): 291-323. Print.

- Claquin, Pascal. Sustainability of EPI: Utopia or Sine Qua Non Condition of Child Survival. Arlington, VA: REACH, 1989. Print.

- Dunst, Carl, Carol Trivette, Carol, and Angela Deal. Supporting and Strengthening Families. Vol. 1: Methods, Strategies and Practices. Cambridge: Brookline, 1994. Print.

- Douglas Easterling, Kaia Gallagher, Jodi Drisko, and Tracy Johnson. Promoting Health by Building Community Capacity: Evidence and Implications for Grantmakers. Denver, Colorado: The Colorado Trust. 1998. Print.

- Fitzsimons, James and Fuller, Louise. "Empowerment and Its Implications for Clinical Practice in Mental Health: A Review." Journal of Mental Health 11.5 (2002): 481-499. Print.

- Frank, Flo and Smith, Anne. The Community Development Handbook. Hull, Quebec: Human Resources Development Canada, 1999. Print.

- Friedman, Lori and Schreiber, Lisa. "Healthy Families America State Systems Development: An Emerging Practice to Ensure Program Growth and Sustainability." Journal of Prevention and Intervention in the Community 34.1/2 (2007): 67-87. Print.

- Gates, Rick and Lee, Mario. Policy Report on Social Development. Vancouver: City of Vancouver, 2005. Print.

- Gill, Carmen and Thériault, Luc. "Valuing Volunteering Without Recognizing the Reality of the Voluntary Sector." Canadian Review of Social Policy 51 (2003): 132-136. Print.

- Goodman, Robert, Speers, Marjorie, McLeroy, Kenneth, Fawcett, Stephen, Kegler, Michelle, Parker, Edith, Smith, Steven, Sterling, Terrie, and Wallerstein, Nina. "Identifying and Defining the Dimensions of Community Capacity to Provide a Basis for Measurement." Health Education and Behavior 25.3 (1998): 258-278, 17. Print.

- Gove, Thomas. Report of the Gove Inquiry into Child Protection in British Columbia. Vancouver: B.C. Government Publications, 1995. Print.

- Hawkins, Robert. "From Self-Sufficiency to Personal and Family Sustainability: A New Paradigm for Social Policy." Journal of Sociology and Social Welfare 32.4 (2005): 77-92. Print.

- Kaplan, Allan. "Capacity Building: Shifting the Paradigm of Practice." Development in Practice 10.3/4) (2000): 517-526. Print.

- Kretzmann, John and McKnight, John. Building Communities From the Inside Out: A Path Toward Finding and Mobilizing a Community's Assets. Chicago, IL: ACTA Publications, 1993. Print. 
- Labonte, Ronald, Woodard, Georgia, Chad, Karen, and Laverack, Glenn. "Community Capacity Building: A Parallel Track for Health Promotion Programs." Canadian Journal of Public Health 93.3 (2002): 181-183. Print.

- Laverack, Glenn. "Building Capable Communities: Experiences in a Rural Fijian Context. Health Promotion International 18.2 (2003): 99-106. Print.

- Laverack, Glenn. Health Promotion Practice: Power and Empowerment. London: Sage Publications, 2004. Print.

- MacLeod, Jennifer, Nelson, Geoffrey, and Desmarais, Sonia. "Promotion of Family Wellness and Prevention of Child Maltreatment: Which Programs Are Effective? (\# 17 E)." Centre of Excellence for Child Welfare. 2004. Web. 28 June. 2011.

- Ontario Prevention Clearinghouse. "Capacity Building for Health Promotion: More Than Bricks and Mortar." Ontario Prevention Clearinghouse. 2002. Web. 28 June. 2011.

- Parker, Edith, Eng, Eugenia, Schulz, Amy, and Israel, Barbara. "Evaluating CommunityBased Health Programs That Seek to Increase Community Capacity. New Directions for Evaluation 83 (1999): 37-54. Print.

- Pender, Nola, Murdaugh, Carolyn, and Parsons, Mary Ann. Health Promotion in Nursing Practice. Upper Saddle River, NJ: Prentice Hall, 2002. Print.

- Poland, Blake. "Social Capital, Social Cohesion, Community Capacity, and Community Empowerment: Variations on a Theme?" Eds. Blake Poland, Lawrence Green, and Irving Rootman, Settings for Health Promotion: Linking Theory and Practice. Thousand Oaks, CA: Sage Publications, 2000. 301-307. Print.

- Poole, Dennis. "Building Community Capacity to Promote Social and Public Health: Challenges for Universities." Health Social Work 22.3 (1997): 163-70. Print.

- Popescu, Marciana, Sugawara, Carmen., Hernandez, Edwin, and Dewan, Smita. "Can Government Funding Strengthen the Third Sector? The Impact of a Capacity Building Program on Faith-Based and Community-Based Organizations. Revista de Asistentå Socialå 4 (2010): 83-101. Print.

- Putnam, Robert. Making Democracy Work: Civic Traditions in Modern Italy. Princeton, NJ: Princeton University Press, 1993. Print.

- Putnam, Robert. "Bowling Alone: America's Declining Social Capital." Journal of Democracy 6 (1995): 65-78. Print.

- Rissel, Chris, Finnegan, John, and Bracht, Neil. "Evaluating Quality and Sustainability: Issues and Insights from the Minnesota Heart Health Program." Health Promotion International 10 (1995): 199-207. Print.

- Rogers, Todd, Howard-Pitney, Beth. and Lee, Hang. An Operational Definition of Local Community Capacity for Tobacco Prevention and Education. Stanford, CA: Stanford Center for Research in Disease Prevention, 1995. Print.

- Scerri, Andy and James, Paul. "Accounting for Sustainability: Combining Qualitative and Quantitative Research in Developing Indicators of Sustainability." International Journal of Social Research Methodology 13.1 (2010): 41-53. Print.

- Scott, Katherine. Funding Matters: The Impact of Canada's New Funding Regime on NonProfit and Voluntary Organizations. Ottawa, ON: Canadian Council on Social Development, 2003. Print.

- Smith, Anne and Frank, Flo. The Community Development Handbook. Ottawa, ON: Human Resources Development Canada, 1999. Print.

- Trocmé, Nino and Chamberland, Claire. "Re-Involving the Community: The Need for a Differential Response to Rising Child Welfare Caseloads in Canada." Community Collaboration and Differential Response: Canadian and International Research and Emerging Models of Practice. Eds. Nino Trocmé, Della Knoke, and Catherine Roy, Ottawa, ON: Centre of Excellence for Child Welfare, 2003. 45-56. Print.

- US Agency for International Development. Sustainability of Development Programs: A Compendium of Donor Experience. Washington, DC: USAID, 1988. Print. 
- Wharf, Brian. (Ed.). Community Work Approaches to Child Welfare.

Peterborough, ON: Broadview Press, 2002. Print.

- White, Marilyn and Marsh, Emily. "Content Analysis: A Flexible Methodology." Library Trends 55.1: 22-45. Print.

- World Health Organization. Intersectoral Action for Health: The Role of Intersectoral Cooperation in National Strategies for Health for All. Geneva:

World Health Organization, 1986. Print 